\title{
Correction to: Elevation of lipid peroxide level and production of hydroxy lipids in cultured Hepa-T1 cells by oxidative stressors
}

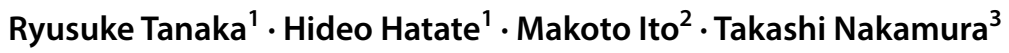

Published online: 15 June 2018

(c) Japanese Society of Fisheries Science 2018

\section{Correction to: Fisheries Science \\ https://doi.org/10.1111/j.1444-2906.2006.01197.x}

The original article was corrected. We had used a cell line, Hepa-T1, in the article as a cell line derived from tilapia liver. However, in April 2018 the provider of Hepa-T1, RIKEN BioResource Research Center (RIKEN BRC), informed us that Hepa-T1 was derived from eel but not tilapia. RIKEN BRC found this misidentification by DNA barcoding of the mitochondrial gene cytochrome $c$ oxidase subunit 1 (COI) (Fig. 1) in a course of pursuing more precise method for species identification of cell lines (Almeida et al. 2016). RIKEN BRC suggested a possibility that Hepa-T1 was replaced with Hepa-E1 cell line which was derived from eel and was deposited from the same scientist.
RIKEN BRC accepted the deposition of these two cell lines simultaneously in March 1995 and could not detect this misidentification by the method available at that time, i.e. isozyme analysis with lactate dehydrogenase and nucleotide phosphorylase.

However, the authors consider this does not affect the main result obtained in this work on the reaction of live fish liver cells against lipid peroxidation.

\section{Reference}

Almeida JL, Cole KD, Plant AL (2016) Standards for cell line authentication and beyond. PLoS Biol 14:e1002476

The authors current affiliation is available in this correction article.

The original article can be found online at https://doi.org/10.1111 /j.1444-2906.2006.01197.x.

Ryusuke Tanaka

rtanaka@cc.miyazaki-u.ac.jp

1 Department of Marine Biology and Environmental Sciences, Faculty of Agriculture, University of Miyazaki, Miyazaki, Japan

2 Department of Bioscience and Biotechnology, Graduate School of Bioresource and Bioenvironmental Sciences, Kyushu University, Fukuoka, Japan

3 Emeritus Professor, Faculty of Agriculture, Kyushu University, Fukuoka, Japan 

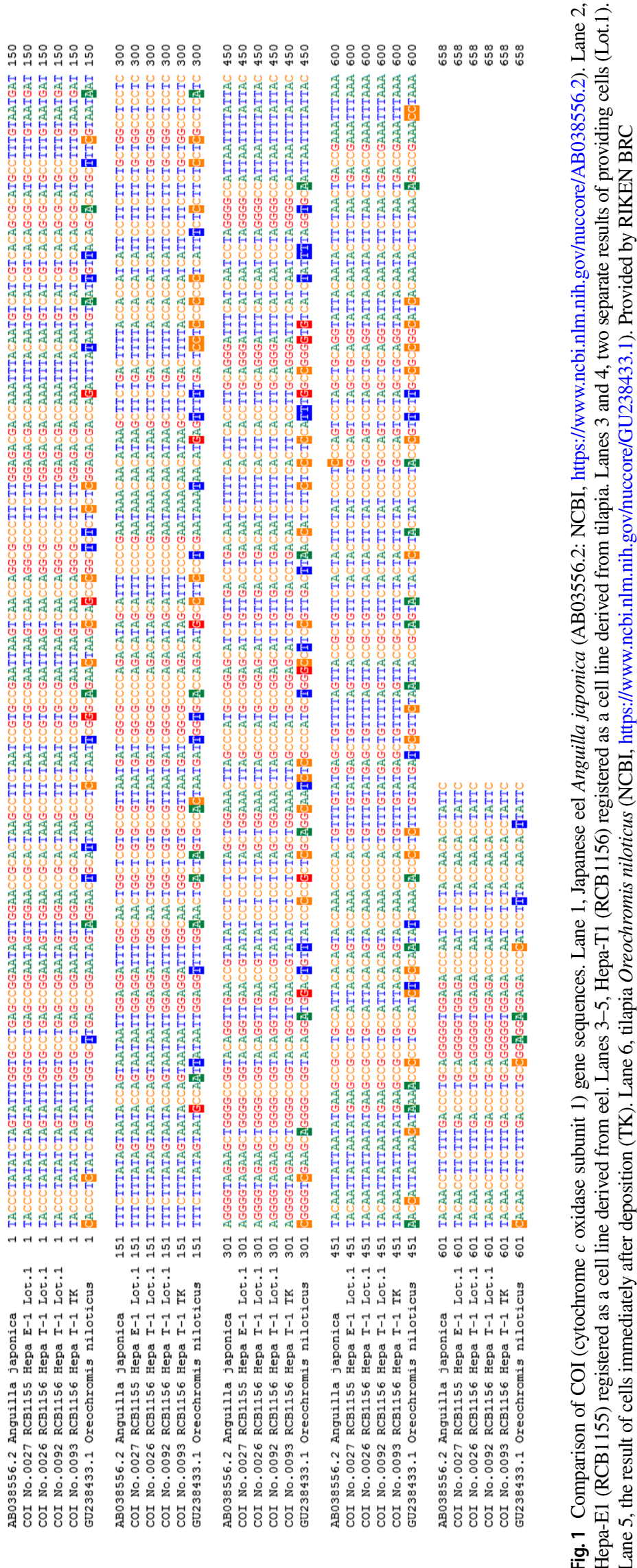